\title{
Ultrastructural study of the corneal epithelium in the recurrent erosion syndrome
}

Dorothy A Aitken, Zeidoon A Beirouty, William R Lee

\begin{abstract}
Background-This study describes the adhesion systems in the corneal epithelium in the recurrent erosion syndrome and the mechanisms by which binucleate and multinucleate cells are formed within the epithelium.

Methods-Twenty five samples of sliding epithelium were obtained from 23 patients and were examined by conventional light and transmission electron microscopy.

Results-The separation of the anchoring system occurred either below the level of the anchoring plaques or at the level of the epithelial cell membrane. Normal and degenerate polymorphonuclear leucocytes were found within and between the epithelial cells and within the anchoring layer. Binucleate and multinucleate cells were found within all the layers of the epithelium as were cysts containing degenerate cellular material.

Conclusion-The presence of leucocytes and degenerate epithelial cells within the sliding epithelium suggests that these are the source of the metalloproteinases which cleave Bowman's layer below the anchoring system. The formation of binucleate and multinucleate giant cells does not appear to occur by fusion of adjacent cells, but rather by nuclear indentation and cleaving due to an abnormal microtubular system in the cytoskeleton.
\end{abstract}

(Brf Ophthalmol 1995; 79: 282-289)

Recurrent epithelial erosion was first described in the ophthalmic literature by Hansen in $1872^{1}$ since when various authors have reported a series of similar and probably interrelated disorders of the corneal epithelium under variously named dystrophies. ${ }^{2-8}$ It has been suggested that these anterior membrane disorders such as Cogan's microcystic dystrophy, Meesman's corneal dystrophy, map dot fingerprint dystrophy, and recurrent epithelial erosion ${ }^{9} 10$ may have a common aetiology and anomalies of the basement membrane are cited as the common factor in these disorders. ${ }^{5-11}$ Apart from these congenital dystrophies, similar findings have been reported following metaherpetic keratitis, ${ }^{12}$ and as a rare complication of both cataract surgery ${ }^{13}$ and epikeratoplasty. ${ }^{14}$ An interesting feature of recurrent erosion is that the epithelium readily separates and slides across the corneal surface and can be easily removed. To investigate the adhesion system in corneal erosion we have studied by light and electron microscopy the corneal epithelium in 23 patients who had developed epithelial sliding usually after minor trauma. A number of additional findings were of interest and these included the presence of binucleate cells, multinucleate giant cells, and polymorphonuclear leucocytes within the cytoplasm of the corneal epithelial cells.

\section{Materials and methods}

\section{CLINICAL OBSERVATIONS}

In 17 of the 25 cases an abrasion was caused by trauma of various types (clinical details are shown in Table 1) including seven who reported two or even three separate and seemingly unrelated incidents. Of the primary injuries five were caused by a finger, two were described as scratches, two involved twigs, two resulted from minor assault, and the remainder reported injuries caused variously by a key, a napkin, scissors, and a snooker cue. Four cases were considered to be idiopathic, one was described as a map dot fingerprint dystrophy, and the other reported an unspecified problem in one eye. Of the repeat traumas, four occurred in the same eye and three reported trauma on a separate occasion in the other eye. The appearance of epithelial sliding occurred any time from 2 days to several years after the initial trauma. All patients were treated with chloramphenicol (Parke Davis, Pontypool) ointment alone or with a combination of

Table 1 Summary of clinical details

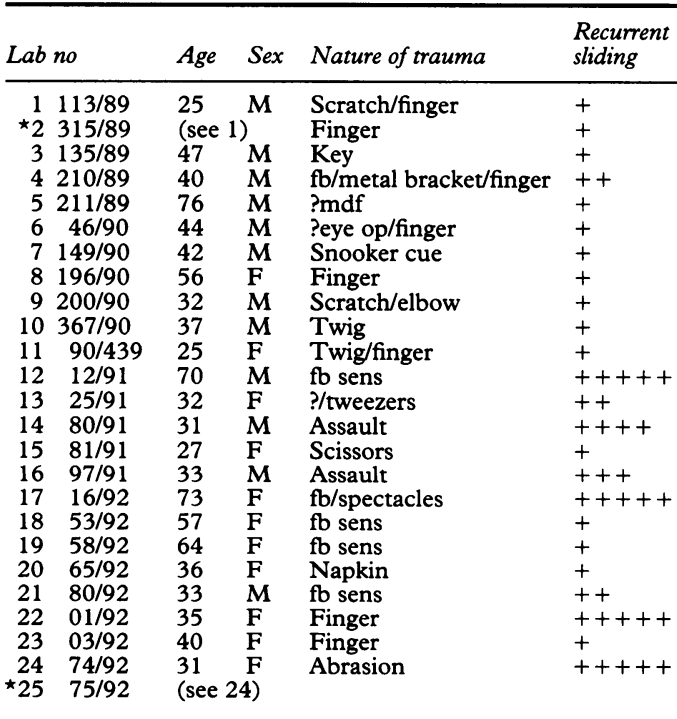

$+=$ Episode of recurrent sliding; ${ }^{\star}=$ second excision; $\mathrm{fb}=$ unspecified foreign body; fb sens $=$ complained of grittiness: no evidence of foreign body; $\mathrm{mdf}=$ map dot fingerprint $?=$ not specified in clinical notes. 


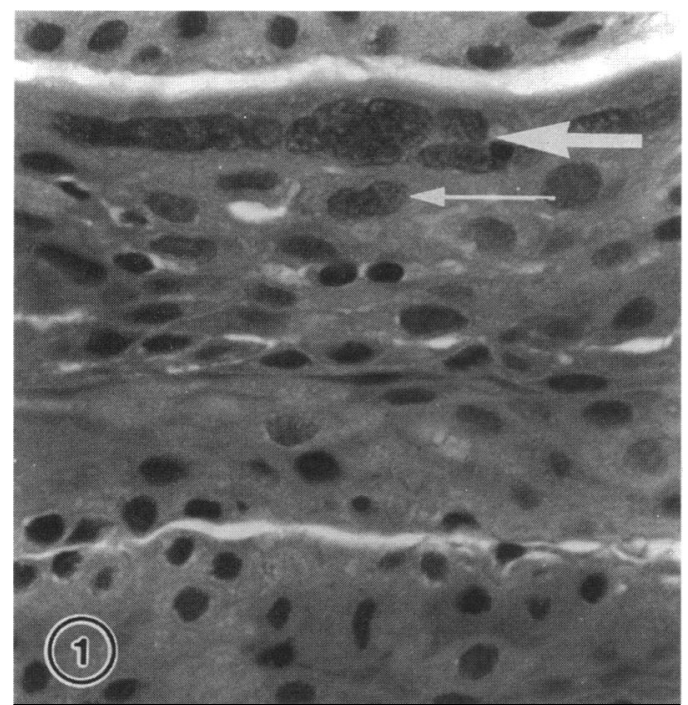

Figure 1 Light micrograph of corneal epithelial biopsy demonstrating binucleate (small arrow) and multinucleate cells (large arrow). Haematoxylin and eosin, magnification $\times 530$.

ointment and drops. The age and sex distributions are shown in Table 1.

MORPHOLOGICAL OBSERVATIONS

After topical anaesthesia with bupivacaine, the epithelial samples were easily excised with scissors and were fixed in $3 \%$ cacodylate buffered glutaraldehyde. Small fragments of folded yellowish/white tissue (1 to $8 \mathrm{~mm}$ ) in length were processed for paraffin histology using conventional stains (haematoxylin and eosin, periodic acid Schiff). Larger specimens were divided and half of the tissue sample was post-fixed in osmium tetroxide, dehydrated in graded alcohols, and embedded in Araldite for conventional electron microscopy. When there was insufficient material for Araldite embedding on the initial submission, the tissue used for paraffin histology was subsequently cleared in xylol, rehydrated, post-fixed, and reprocessed as above for transmission electron microscopy.

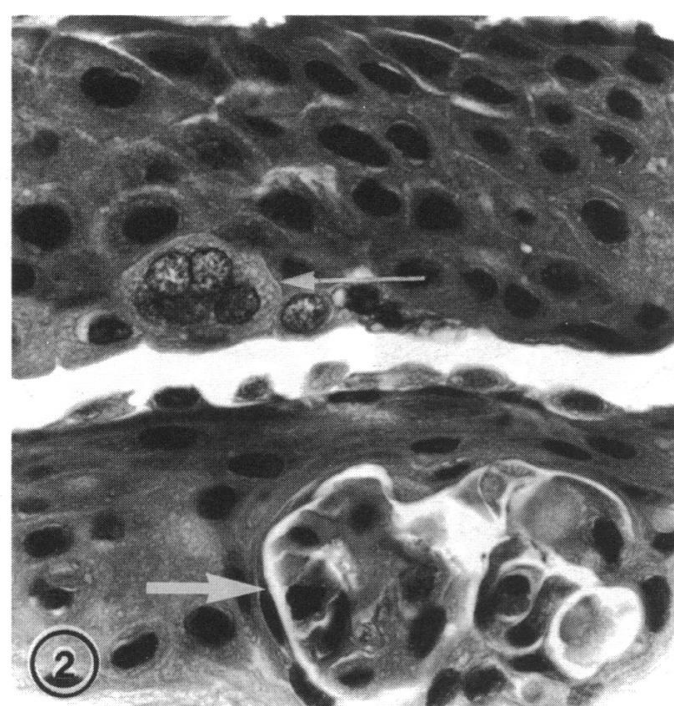

Figure 2 Another corneal epithelial biopsy showing multinucleate cells (small arrow) and encysted cells (large arrow). Haematoxylin and eosin, magnification $\times 530$.

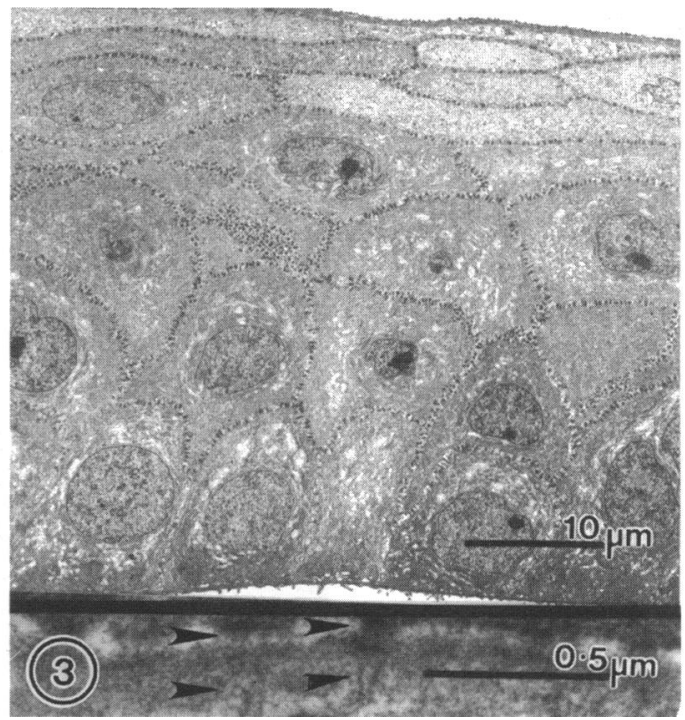

Figure 3 Electron micrograph of a detached epithelium with well organised architecture. Inset: from another specimen with attached Bowman's layer and anchoring complexes (arrowheads).

\section{MORPHOLOGICAL FINDINGS}

\section{Light microscopy}

In the majority of specimens, sections cut transversely across the rolled up specimen revealed the full thickness of the epithelial layers. In the 25 cases examined by light microscopy the most notable feature in paraffin sections and toluidine blue stained semithin sections was the presence of multinucleate giant cells, binucleate cells, or both (Figs 1 and 2). Some of these cells reached a large size and contained as many as 16 nuclei and multinucleate giant cells and binucleate cells were located in all cell layers. Cysts containing cell debris were present in 18 specimens (Fig 2): in many specimens polymorphonuclear leucocytes were conspicuous.

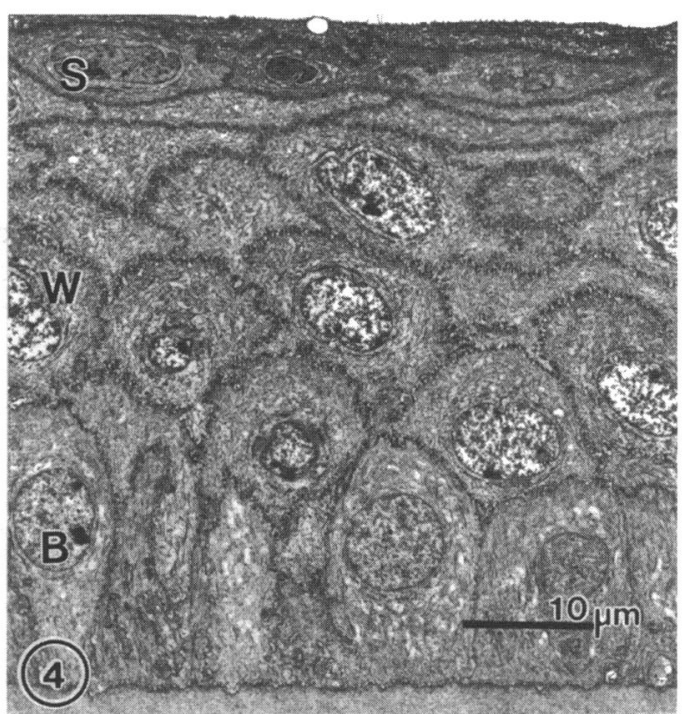

Figure 4 Normal control human corneal epithelium for comparison showing single columnar basal layer $(B)$, two to three layers of wing or polygonal cells (W), and two to three rows of superficial cells (S). The epithelium is firmly attached to an intact Bowman's layer. 


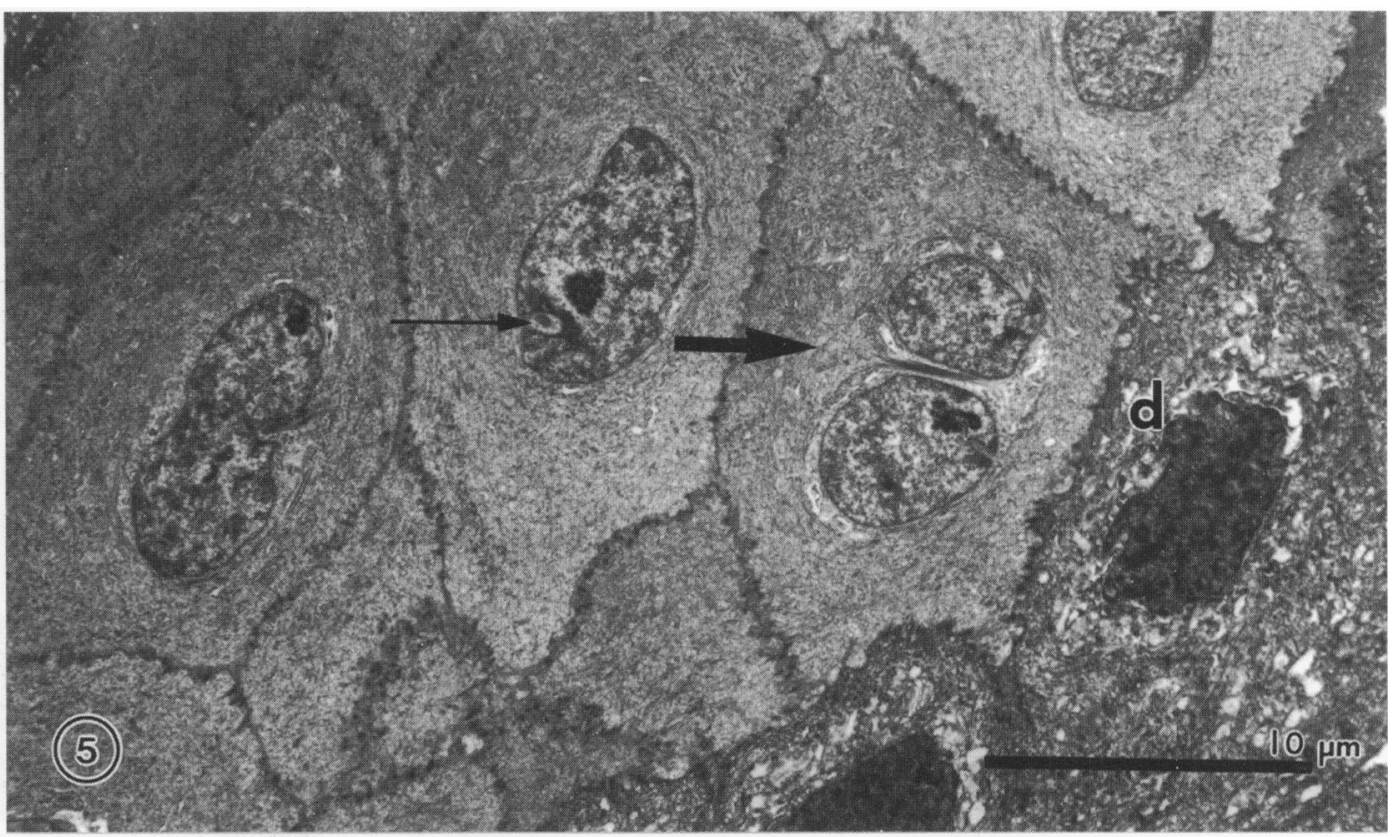

Figure 5 Epithelial cells with numerous desmosomes. Note binucleate cell (large arrow) and a cell with a nuclear cleft (small arrow). Filaments are condensed in the clefts in the nuclei. Degenerate cells (d) are also present.

\section{Electron microscopy}

The epithelial cell organelles were preserved in each specimen and this was comparable with normal control tissue (Figs 3 and 4). In most of the pathological specimens it was possible to identify the basement membrane of the epithelium and anchoring filaments and plaques were persisting in the majority (Fig 3), but the pattern was variable within an individual specimen. In some cases the cell membrane was the limiting layer at the base of the epithelium. Where the basement membrane complex was preserved, the outer zone of Bowman's layer was present and hemidesmosomes, anchoring plaques, and fibrils could be demonstrated (Fig 3, inset). The epithelial cells throughout all layers were attached by plentiful desmosomes (Figs 3 and 5). Occasionally some cells in the superficial or basal layer were denser and less well preserved than normal but this was possibly an in vivo drying artefact or could have been produced by handling during the excision procedure (Fig 5). Cells with nuclear clefts

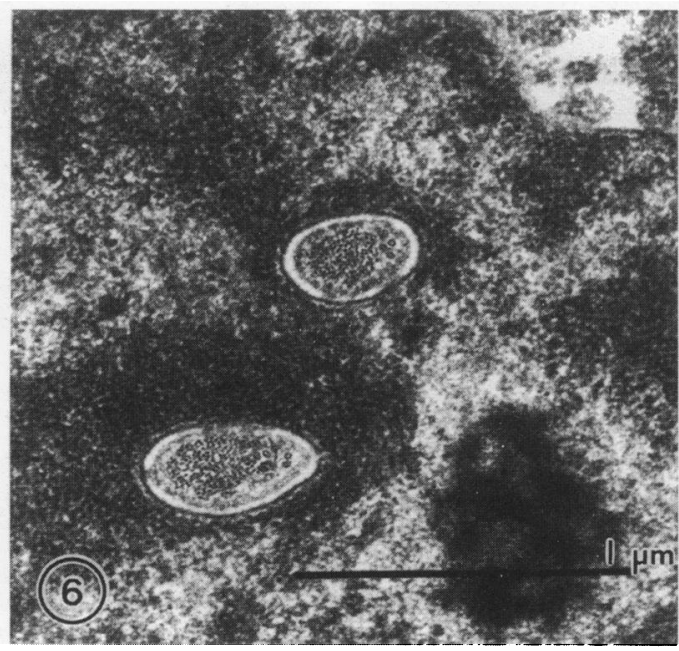

Figure 6 Filaments and tubules in cross section within the nuclear holes as shown in Figure 5. were numerous and bands of condensed tonofibrils surrounded some of these nuclei with indentation where the clefts occurred (Fig 5). At higher magnification fibrillar and tubular structures (Figs 6 and 7) were identified in the nuclear clefts and between the lobes of the nuclei. Bundles of microfibrils and microtubules could be demonstrated in both longitudinal and transverse section where they occupied 'nuclear holes' (Fig 6). In some larger cells the aggregates of filaments and tubules appear to cleave the nucleus (Fig 7). Cells apparently containing more than two nuclei also appeared in all the layers of the epithelium (Figs 8-10) and in some daughter nuclei, dissolution and dispersion of nuclear chromatin suggested a degenerative process. Cells containing up to as many as eight nuclear profiles were also identified in all the epithelial layers (Figs 8-10). These 'multinucleate' giant cells were, in most instances, firmly attached to the mononuclear neighbouring cells by desmosomes and the cytoplasm had the

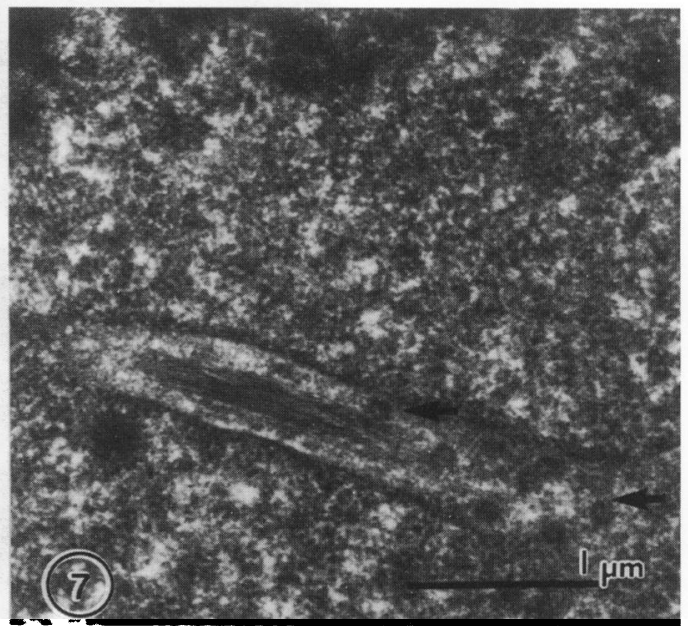

Figure 7 Condensed filaments and some tubular structures (arrows) within a clefi in a binucleate cell. 


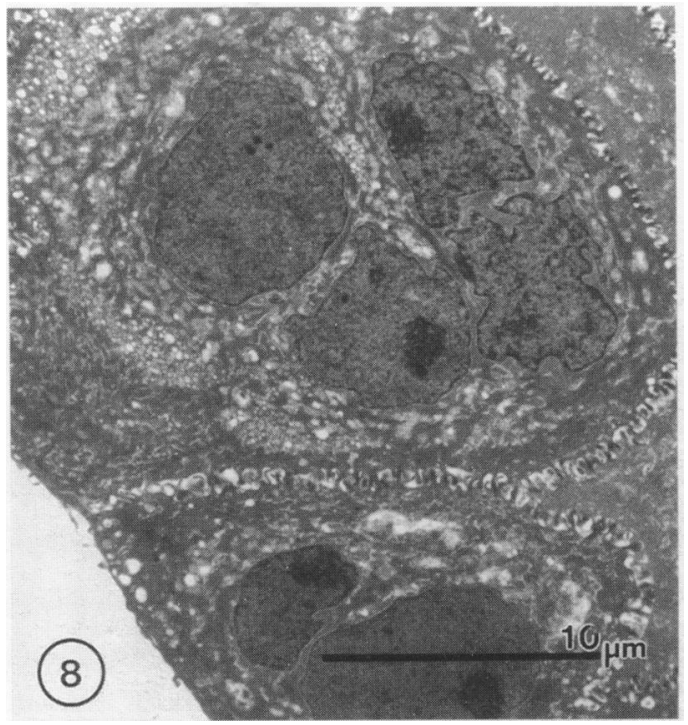

Figure 8 Giant cell containing four apparently separate nuclei each with a prominent nucleolus in the basal layer. The cytoplasm is rarefied and contains bundles of condensed tonofibrils.

characteristic paucity of organelles that is typical of the corneal epithelium. There was no evidence of desmosomal residues within the cytoplasm of the cells containing numerous nuclear profiles - a feature which could indicate cell fusion. In some areas the giant cells had pale oval nuclei (Fig 9) whereas others showed clumping of nuclear chromatin (Fig 8) even in undisputed multinucleate giant cells (Fig 10). Intraepithelial polymorphonuclear leucocytes were observed in many specimens (see Table 2) and were well preserved in general (Fig 11), but a significant number were degenerate and showed secondary phagolysosome formation (Fig 12). The morphology suggested that the inflammatory cells had been phagocytosed by the epithelial cells (Figs 12 and 13) and that this process progressed to encystment of condensed protein derived from cellular degradation (Fig 13). A similar process of phagocytosis of cells was observed in several

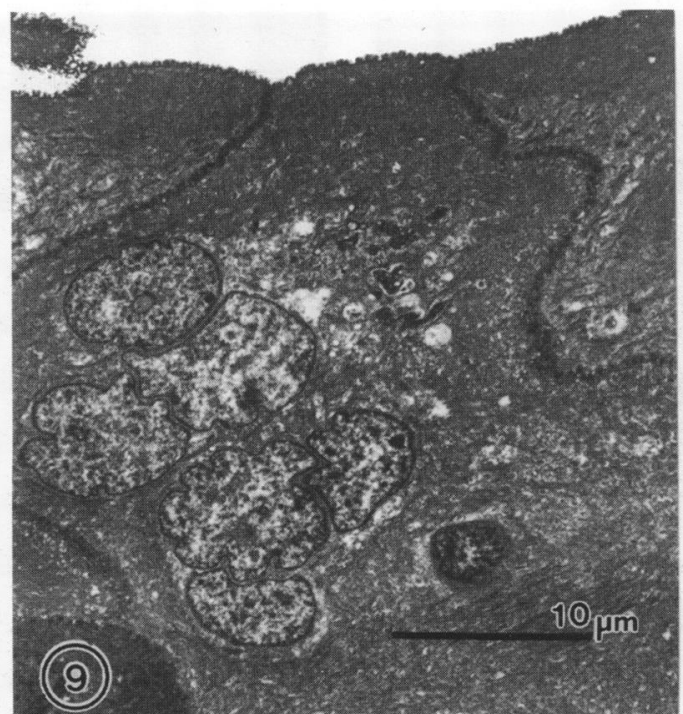

Figure 9 Large cell in the superficial layer with prominent nuclear segmentation. The nuclear chromatin is finely granular and sparse suggesting a degenerative process.

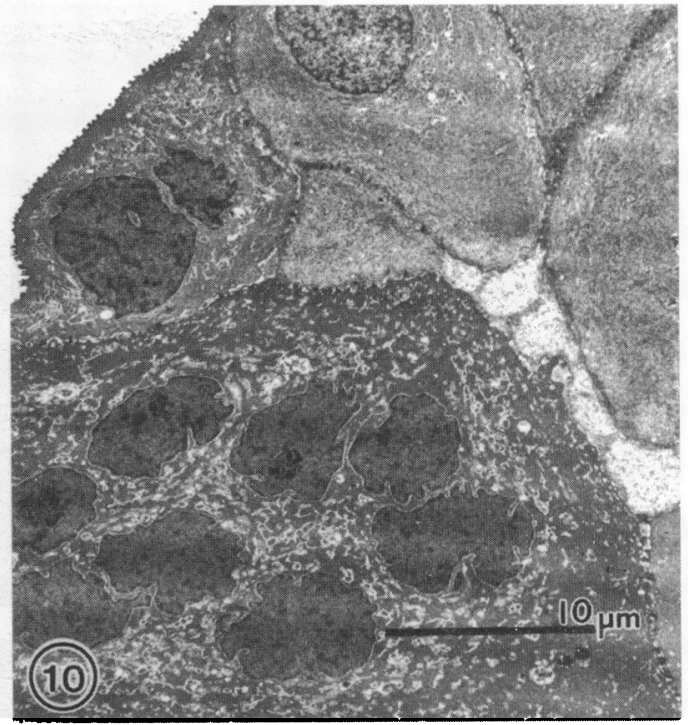

Figure 10 Part of a multinucleate giant cell with condensed nuclear chromatin and cytoplasmic

condensations similar to those seen in normal desquamating cells.

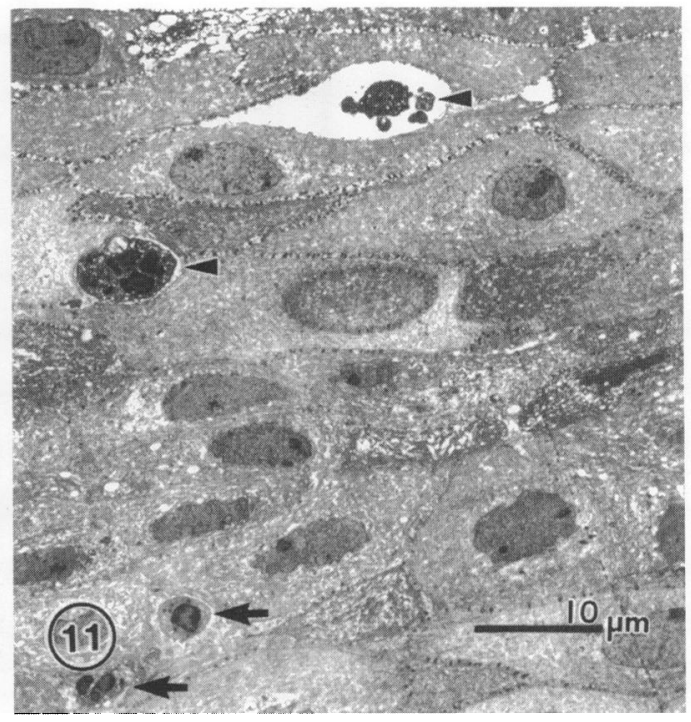

Figure 11 Normal (arrows) and degenerate leucocytes (arrowheads) within the sliding epithelium. Cystic spaces containing degenerate material are present within the superficial layers.

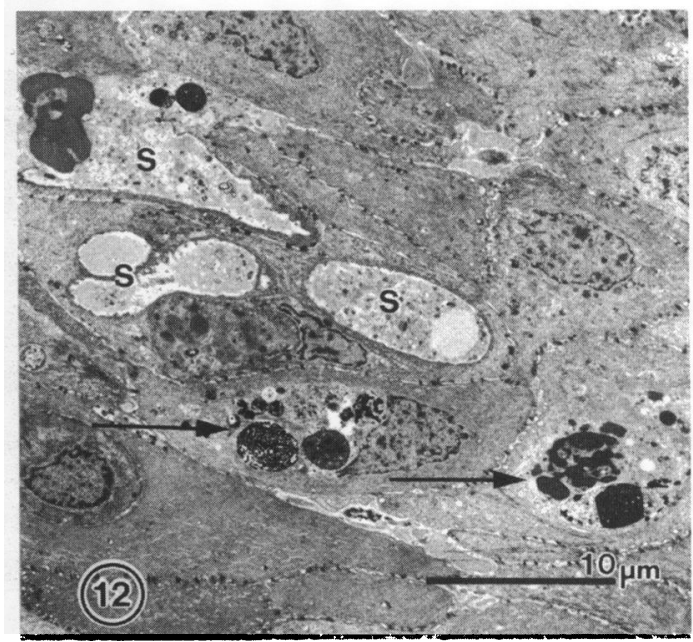

Figure 12 Degenerate polymorphonuclear leucocytes within the epithelium (arrows). It appears that some epithelial cells have endocytosed the leucocytes. Cystic spaces (s) contain debris. 


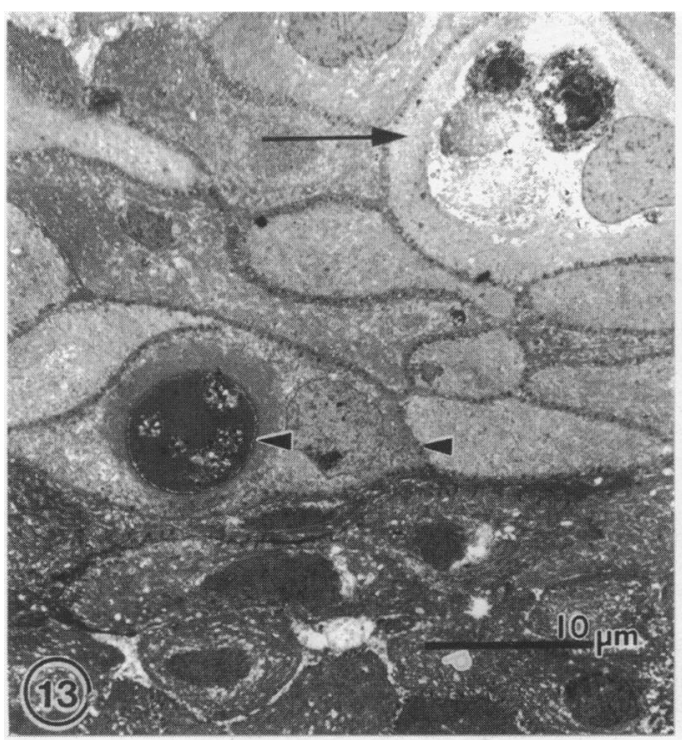

Figure 13 An epithelial cell (arrow) contains two identifiable polymorphonuclear leucocytes and some nuclear debris. A similar epithelial cell (arrowheads) contains a circular mass of compact debris.

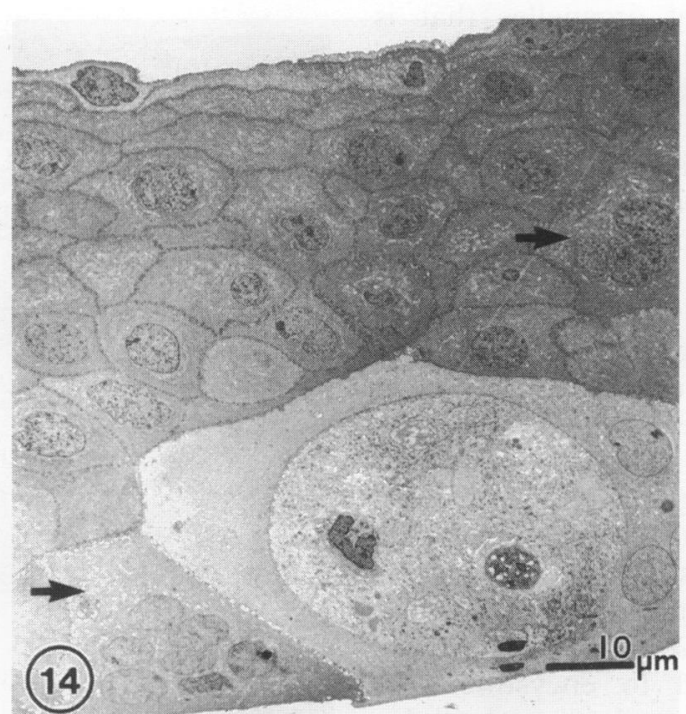

Figure 14 Within the basal layer there is a multinucleate cell which contains a circular inclusion containing identifiable cells: note the adjacent multinucleate giant cells (arrows).

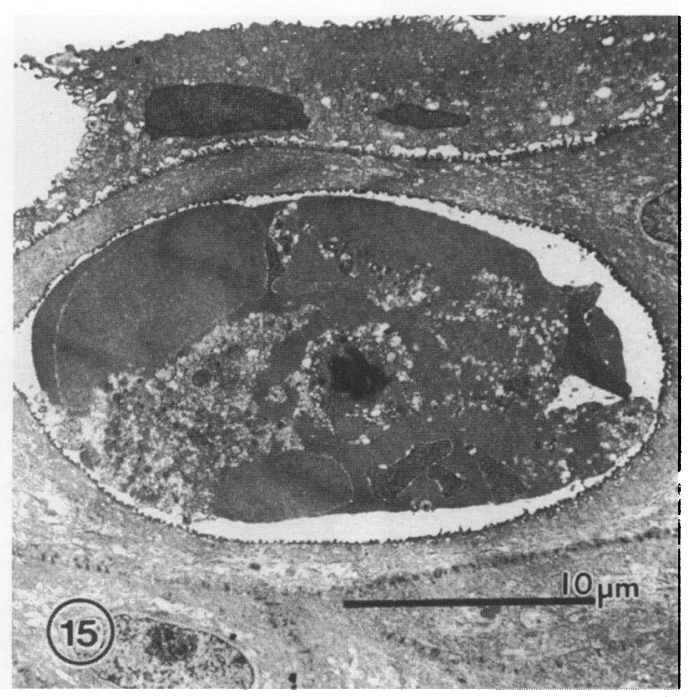

Figure 15 A large mass of condensed proteinaceous material and cellular debris seemingly within an enlarged epithelial cell.

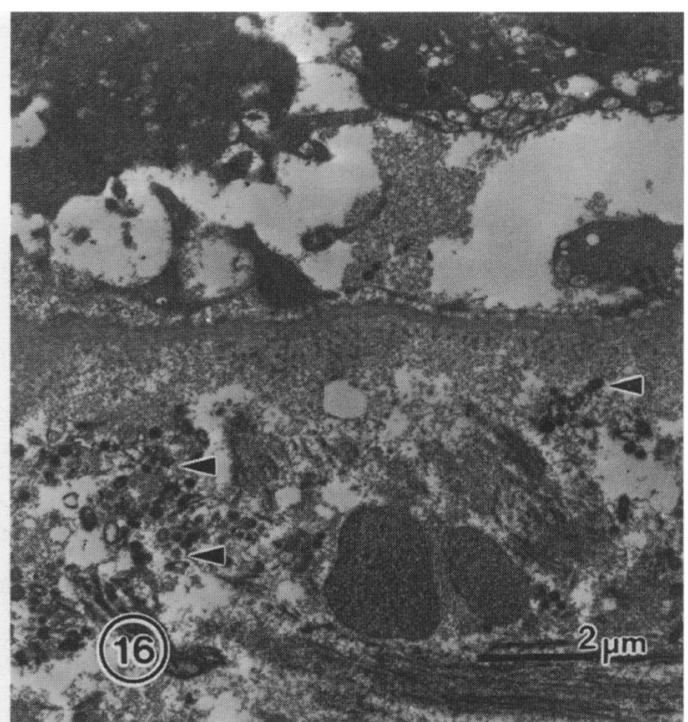

Figure 16 In a specimen in which Bowman's layer was retained, the remnants of a degenerate polymorphonuclear leucocyte (arrowhead) are identified.

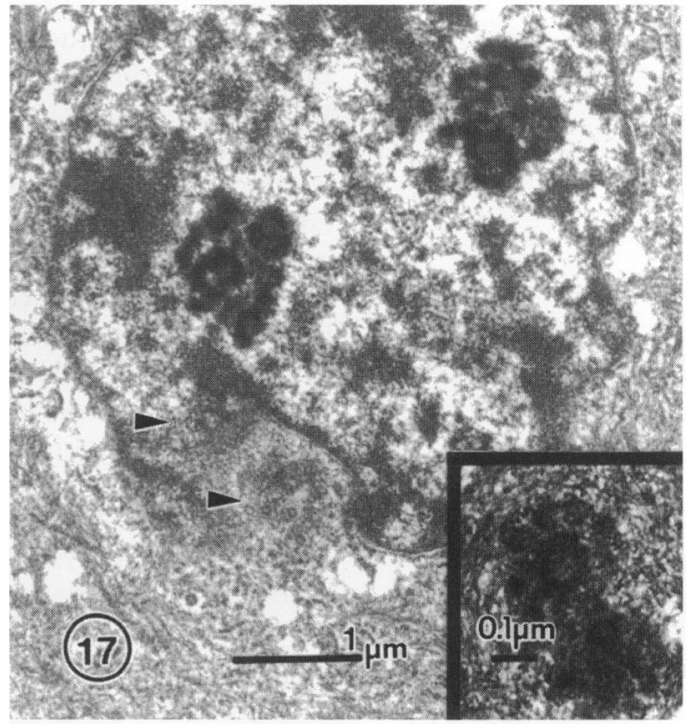

Figure 17 A mononuclear cell with a nucleus containing two prominent nucleoli and 'atypical' centrioles

(arrowheads) within a nuclear cleft. Inset: a centriole pair with satellite tubular arrays from another cell.

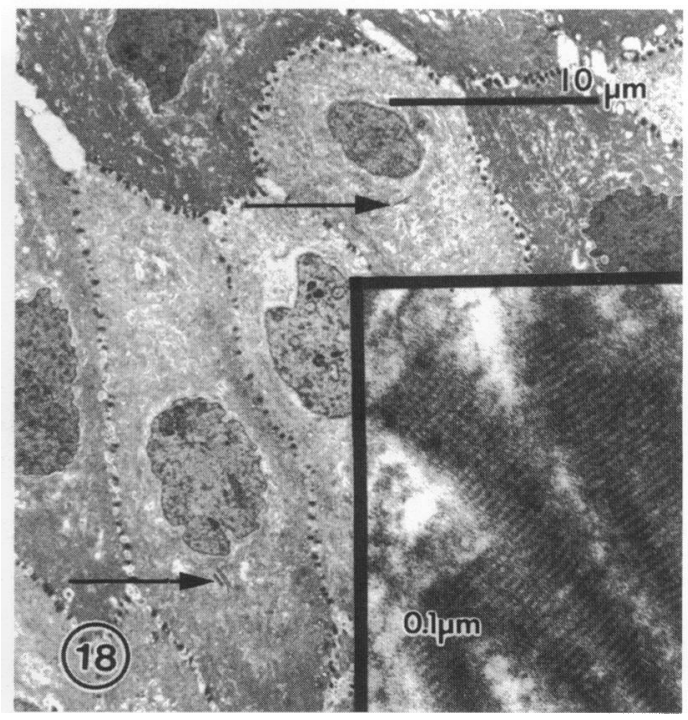

Figure 18 Perinuclear rod-like structures in the epithelium (arrows) have a banded crystalline structure at high magnification (inset). 
Table 2 Comparison of morphological features

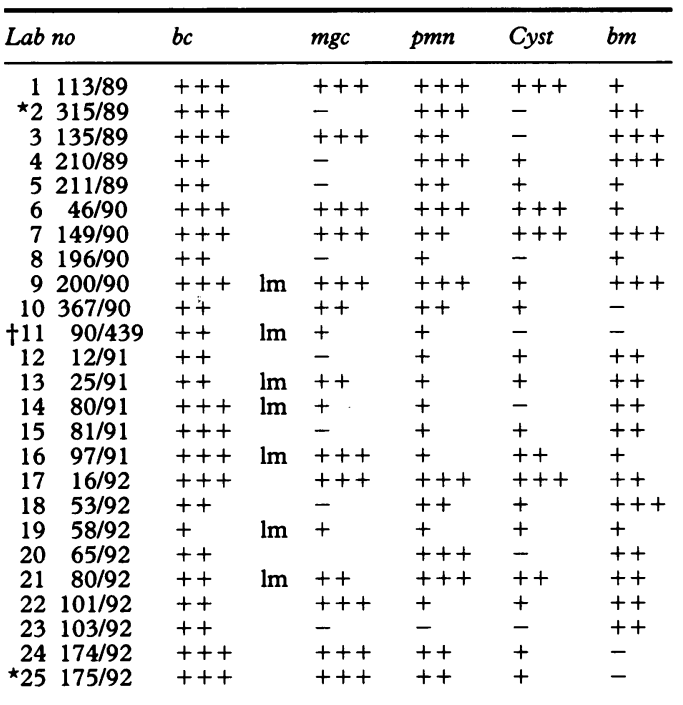

*=Second excision; $1 \mathrm{~m}=$ visualised by light microscopy only; $\dagger=$ not submitted for electron microscopy.

$\mathrm{bc}=$ binucleate cell; $\mathrm{mgc}=$ multinucleate giant cell;

$\mathrm{pmn}=$ polymorphonuclear leucocyte; $\mathrm{bm}=$ basement membrane.

of the multinucleate giant cells and the spectrum extended from recognisable cellular constituents (Fig 14) to large cystic masses of fibrillogranular debris (Fig 15). Debris derived from polymorphonuclear leucocytes was located below the level of the anchoring system in some specimens (Fig 16).

An interesting feature of the sliding epithelium was the presence of epithelial cells with atypical nuclear characteristics - for example, prominent nucleoli, centrioles, and a coarse nucleolonema (Fig 17). This feature was conspicuous in most of the specimens (Figs 3, 5, 6, 8, 11), and centrioles, assemblies of tubules, and dense aggregations of filaments were also common findings in the biopsies. In several specimens dark rod-like structures were observed adjacent to the nucleus (Fig 18) and at higher magnification periodicity could be demonstrated: the nature and significance of this feature are not known.

The morphological features are summarised in Table 2.

\section{Discussion}

A review by Chandler ${ }^{15}$ in 1945 gave a comprehensive history of the early work dealing with recurrent epithelial erosion. At this time, investigators considered that the pathogenesis included a mild form of oedema caused by a thin layer of fluid under the epithelium, which increased at times of relapse. It was suggested that a defective endothelium was the cause of the persistent epithelial oedema and the aetiology was assumed to be neuropathic. In 1964 Cogan et al described a microcystic dystrophy of the cornea. ${ }^{2}$ This and subsequent reports $^{3-10}$ described a variety of anterior corneal dystrophies with a pathology similar in some respects to the intraepithelial cystic degeneration which we describe in the present material. Microcysts containing what appeared to be cellular debris have been well docu- mented clinically but only rarely by light and electron microscopy. 245613 Tonofibrils were prominent in the sliding epithelial cells in our material. The appearances were similar to those described as abundant in an early report of recurrent epithelial erosion ${ }^{16}$ and tonofibrils are known to be present to a much lesser extent in normal corneal epithelium. ${ }^{17} \mathrm{~A}$ more recent significant report on epithelial abnormalities following epikeratoplasty illustrates in two cases, an increase in tonofibrils which impinged on the nucleus to the extent that binuclear profiles were formed. ${ }^{14}$ In our material binuclear profiles were identified in all the specimens examined by electron microscopy and were present at all levels in the corneal epithelium. While the impingement of tonofibrils on the nucleus has been illustrated in the normal cornea, ${ }^{17}$ our demonstration of the presence of microtubular structures within deep indentations in the nuclei suggests that this process is of importance in the formation of binucleate cells.

The abundance of multinucleate giant cells in the sliding epithelium in recurrent erosions was an unexpected feature when the specimens were originally examined by light microscopy. Multinucleate giant cells were identified in the sliding epithelium in 17 cases by light microscopy in paraffin sections. In the thinner sections used for electron microscopy a nucleus with numerous indentations could appear as multinucleate. Also at the electron microscopic level the section may only pass through one of several nuclei present at different levels within a cell which would have been identified as multinucleate by light microscopy. This latter feature of microscopy could explain why multinucleate giant cells were found only in nine specimens at the electron microscopic level. Herpetic giant cells have been described in the pathology of herpes simplex keratoiritis, ${ }^{18}$ but the present morphological study did not provide morphological evidence to indicate a viral infection which was also excluded by virological analysis. The present morphology did, however, resemble the descriptions provided in a single case report of fingerprint dystrophy, ${ }^{7}$ a familial condition in which the epithelial attachment system is defective and in which there is some similarity to recurrent corneal erosion. Brodrick et $a l^{7}$ illustrated a multinucleate giant cell in the basal layer and multinucleate giant cells encysting degenerate cellular material. An alignment in a columnar configuration indicated that as many as 12 cells had fused to form this giant cell. ${ }^{7}$ Some of the multinucleate giant cells in the examples of epithelial erosion in our series were similar to those described as fusing cells by Brodrick et al, ${ }^{7}$ but the majority were dissimilar in architecture and outline (both circular and elongated) and were not confined solely to the basal layer.

The mechanism by which multinucleate cells are formed is as yet undetermined. It has been suggested that multinucleate giant cell formation in epithelial cells is due to biochemical factors produced by degenerating cells. $^{7}$ The presence of cysts containing 
degenerating cells was a common feature in our material and this adds support to the previous suggestion. ${ }^{7}$ Similarly it has been shown in multinucleate tumour cell formation that chemically induced changes in membrane properties allow the close apposition and ultimate fusion of cell membranes. ${ }^{19}$ However, we were unable to identify intracytoplasmic desmosomes which would indicate cell membrane fusion and incorporation. Alternatively it is also accepted that where mitosis occurs without cell cytokinesis, giant cells may also form: certain multinucleate giant cells are thought to form in this fashion - for example, megakaryocytes and some types of neoplastic cells. ${ }^{20}$ We cannot discount the possibility that the multinucleate cells in the corneal epithelium were formed by mitosis without cytokinesis, but on no occasion were mitotic figures observed either by light or transmission electron microscopy. Multinucleate cells forming in the absence of cytokinesis have been shown to contain multiple centrioles ${ }^{20}$ which are derived from microtubules.

In the normal attached corneal epithelium, microtubules are only present in the mitotic spindle. ${ }^{21}$ Centrioles are present but rarely observed in the basal cell layer and almost never seen in the wing and superficial cell layers. ${ }^{22}$ However, it has been shown that during experimental wound healing the cytoplasmic extensions contain microtubules. ${ }^{21}$ In the present study microtubules were abundant (Figs 5, 6, and 7) and centrioles were a common occurrence in all layers of the corneal epithelium (Fig 17). In normal epithelium two centrioles are usually visible before mitosis, two daughters forming as a rule at right angles to the parent but in the present material these structures were not arrayed at right angles and this abnormality is an indication of nuclear polyploidy. ${ }^{23}$ It is known that tubulin assembly in vitro can be arrested or stimulated by a variety of drugs and conditions, ${ }^{23}$ and we can only speculate that some similar mechanism was triggered during epithelial repair following both the initial trauma and subsequent episodes of erosion. Chloramphenicol, the common therapeutic agent prescribed in this series of patients, has never been suspected of having an antimitotic effect and we do not consider this drug as the aetiological agent.

The most interesting feature in recurrent corneal erosion is the rapidity with which the epithelium loses adhesion and slides freely. The importance of anchoring systems in maintaining epithelial adhesion has long been established ${ }^{24}$ and defective anchoring systems have been incriminated in epithelial erosions and other anterior disorders. ${ }^{2-5} 9$ 12-14 1624 The previous literature must be reconsidered in the light of recent developments in the understanding of normal corneal adhesion mechanisms. Collagen types I, III, V, VI, and laminin have been located in the anchoring plaques of the subepithelial basement membrane complex ${ }^{2526}$ and collagen type VII has been identified as a major structural component in the anchoring fibrils. ${ }^{27} 28$ Laminin and type VI collagen, ${ }^{25} 26$ and type IV collagen plus the carboxyl terminal domain of type VII have been located in the anchoring plaques. ${ }^{27}$ The epithelium is also thought to require the adhesive macromolecules fibronectin and laminin to mediate attachment of the basal cells to the collagen type IV and heparan sulphate of the basal lamina. ${ }^{29}$ Fibronectin is also considered necessary for successful epithelial attachment and migration during resurfacing following minor injury ${ }^{29}$ and it has been shown that the extracellular matrix molecules can influence and organise the basal cell surface and also the actin rich cortex of basal cells. ${ }^{3031}$ The binding sites for the extracellular matrix molecules are protease sensitive. ${ }^{31}$ Polymorphonuclear leucocytes, which showed a variety of degenerative changes and were located in all levels of the epithelium, were present in our cases of recurrent erosion. The lysosomal constituents of these leucocytes presumably released proteases which caused proteolytic degradation of the stroma $^{15}$ and basement membrane. ${ }^{31}$ The importance of metalloproteinases in the degradation of the epithelial basement membrane has recently been emphasised and the best characterised of these is collagenase. ${ }^{32} \mathrm{~A} 92 \mathrm{kD}$ (type IV and V) collagenase MMP-9 is synthesised by neutrophils, macrophages, and by corneal epithelial cells. ${ }^{32}$ This collagenase is one of the two gelatinase subtypes of the MMPs found in the cornea and is implicated in both cellular invasion and degradation of epithelial basement membrane before corneal ulceration. ${ }^{32} 33$

Thus there are numerous complicated interactions between structural proteins and the enzyme systems which control their synthesis and degradation and these mechanisms may be regulated by various mediators such as growth factors released from epithelial cells and keratocytes. ${ }^{34}$ It is hoped that this description of the ultrastructural pathology of recurrent erosion system and its spectrum of morphological changes in the corneal epithelium and its anchoring system may aid in exposing the factors responsible for the susceptibility of this group of patients to an uncomfortable and recalcitrant disease.

1 Hansen E. Intermittirinde keratitis vesiculosa neuralgica af traumatisk Oprindelse. Hospitalstid 1872; 201: Aug 15. Cited by Chandler ${ }^{15}$.

2 Cogan D, Donaldson D, Kuwabara T, Marshall D. Microcystic dystrophy of corneal epithelium. Trans $A m$ Ophthalmol Soc 1964; 62: 213-25.

3 Kuwabara T, Ciccarelli EC. Meesmann's corneal dystrophy: a pathology study. Arch Ophthalmol 1964; 71: 676-82.

4 Guerry D. Observations on Cogan's microcystic dystrophy of the corneal epithelium. Am $\mathcal{F}$ Ophthalmol 1966; 62: of the 73 .

5 Cogan DG, Kuwabara T, Donaldson DD, Collins E. Microcystic dystrophy of the cornea: a partial explanation for its pathogenesis. Arch Ophthalmol 1974; 92: 470-4.

6 Rodrigues MM, Fine BS, Laibson PR, Zimmerman LE. Disorders of the corneal epithelium: a clinicopathologic study of dot, geographic and fingerprint patterns. Arch Ophthalmol 1974; 92: 475-82.

7 Brodrick JD, Dark AJ, Peace GW. Fingerprint dystrophy of the cornea. Arch Ophthalmol 1974; 92: 483-9.

8 Bron AJ, Brown NA. Some superficial corneal disorders. Trans Ophthalmol Soc UK 1971; 91: 13-30.

9 Tripathi RC, Bron AJ. Ultrastructural study of nontraumatic recurrent corneal erosion. $\mathrm{Br} \mathcal{f}$ Ophthalmol 1972; 56: 73-85.

10 Bron AJ, Burgess EP. Inherited recurrent corneal erosion Trans Ophthalmol Soc UK 1981; 101: 239-43.

11 Fogle JA, Kenyon KR, Stark WJ, Green WR. Defective epithelial adhesion in anterior corneal dystrophies. Am $\mathcal{f}$ Ophthalmol 1975; 79: 925-40. 
12 Kaufman HE. Epithelial erosion syndrome: metaherpetic keratitis. Am f Ophthalmol 1984; 56: 983-7.

13 Brodrick JD. Anterior membrane dystrophy following cataract extraction. Br f Ophthalmol 1979; 63: 331-5.

14 Frangieh GT, Kenyon KR, Wagoner MD, Hanninen $L$, John T, Steinart RF. Epithelial abnormalities and sterile ulceration of epikeratoplasty grafts. Ophthalmology 1988; 95: 213-27.

15 Chandler PA. Recurrent erosion of the cornea. Am $f$ Ophthalmol 1945; 28: 355-63.

16 Goldman JN, Dohlman CH, Kravitt BA. The basement membrane of the human cornea in recurrent erosion syndrome. Trans Am Acad Ophthalmol Otolaryngol 1969, 73: 471-81.

17 Jakus MA. Ocular fine structure. Boston: Little Brown, 1964 16.

18 Hogan MJ, Kimura SJ, Thygeson P. Pathology of herpes simplex kerato-iritis. 9 Chambers TJ. Multinucleate giant cells. $\mathcal{f}$ Pathol 1978; 126 125-48.

20 Ghadially FN. Ultrastructural pathology of the cell and matrix. London: Butterworths, 1982: 181-90.

21 Gipson IK. Cytoplasmic filaments: their role in motility and cell shape. Invest Ophthalmol Vis Sci 1977; 16: 1081-4. 22 Hogan MJ, Alvarado JA, Weddell JE. Histology of the human eye. Toronto: Saunders, 1971: 65-82.

23 Dustin P. Microtubules. New York: Springer-Verlag, 1984: $131-41$.

24 Khodadoust AA, Silverstein AM, Kenyon KK, Dowling JE. Adhesion of regenerating corneal epithelium: the role of basement membrane. Am f Ophthalmol 1968; 65: 339-48.

25 Marshall GE, Konstas AG, Lee WR. Immunogold fine structural localisation of extracellular matrix components in aged human cornea. I. Types I-IV collagen and laminin. Graefes Arch Clin Ophthalmol 1991; 229: 157-63.

26 Marshall GE, Konstas AG, Lee WR. Immunogold fine structural localization of extracellular matrix components in aged human cornea. II. Collagen types V and VI. Graefes Arch Clin Ophthalmol 1991; 229: 164-71.

27 Keene DR, Sakai LY, Lunstrum GP, Morris NP, Burgeson RE. Type VII collagen forms an extended network of anchoring fibrils. $\mathcal{F}$ Cell Biol 1987; 104: 611-21.

28 Gipson IK, Spurr-Michaud SJ, Tisdale AS. Anchoring fibrils form a complex network in human and rabbit cornea. Invest Ophthalmol Vis Sci 1987; 28: 212-20.

29 Berman $M$. The pathogenesis of corneal epithelial defects. Acta Ophthalmol 1989; 67 (suppl 192): 55-64.

30 Sugrue SP, Hay ED. Response of basal epithelial cell surface and cytoskeleton to solubilised extracellular matrix molecules. f Cell Biol 1981; 91: 45-54.

31 Sugrue SP, Hay ED. The identification of extracellular matrix (ECM) binding sites on the basal surface of matrix (ECM) binding sites on the basal surface of embryonic corneal epithelium and the effect of ECM binding on epithelial

32 Matsubara M, Girard MT, Kublin CL, Cintron C, Fini ME. Differential roles for two gelatinolytic enzymes of the matrix metalloproteinase family in the remodelling cornea. Dev Biol 1991; 147: 425-39.

33 Fini ME, Girard MT. Expression of collagenolytic/gelatinolytic metalloproteinases by normal cornea. Invest Ophthalmol Vis Sci 1990; 31: 1779-88.

34 Tervo T, van Settin G-B, Paallysaho T, Tarkkanan A Tervo K. Wound healing of the ocular surface. Ann Med 1992; 24: 19-27. 